This is an open access article distributed under the terms of the Creative Commons BY-NC-ND Licence

\title{
Effects hydrogen sulfide on the antioxidant system and membrane stability in mitochondria of Malus hupehensis under NaCl stress
}

\author{
G.-Q. WEI ${ }^{1,2}$, W.-W. ZHANG ${ }^{1}$, H. CAO ${ }^{1}$, S.-S. YUE ${ }^{1}$, P. LI ${ }^{1}$, and H.-Q. YANG ${ }^{1 *}$ \\ College of Horticulture Science and Engineering, State Key Laboratory of Crop Biology, \\ Shandong Agricultural University, Tai'an, Shandong 271018, P.R. China ${ }^{1}$ \\ Shandong Institute of Pomology, Shandong Academy of Agricultural Sciences, Taian, Shandong 271000, P.R. China ${ }^{2}$
}

\begin{abstract}
Salt stress is one of the most critical environmental factors limiting plant growth, and hydrogen sulfide $\left(\mathrm{H}_{2} \mathrm{~S}\right)$ can play a role in plant responses to this stress. To investigate the effects of $\mathrm{H}_{2} \mathrm{~S}$ on mitochondrial functions under salt stress, we treated Malus hupehensis Rehd. var. pingyiensis germinating seeds with an $85 \mathrm{mM} \mathrm{NaCl}$ solution with or without an $\mathrm{H}_{2} \mathrm{~S}$ donor sodium hydrosulfide (NaHS) and $\mathrm{H}_{2} \mathrm{~S}$ scavenger hypotaurine (HT). Then, hydrogen peroxide $\left(\mathrm{H}_{2} \mathrm{O}_{2}\right)$ content and antioxidant enzyme activities were measured in mitochondria of seedling roots. Our results show that the application of $0.05 \mathrm{mM}$ NaHS rescued an NaCl-induced inhibition of root elongation, decreased $\mathrm{H}_{2} \mathrm{O}_{2}$ content, and enhanced superoxide dismutase (SOD), guaiacol peroxidase (POD), and catalase (CAT) activities in the mitochondria compared to $\mathrm{NaCl}$ treatment alone. It was also found that $0.05 \mathrm{mM}$ NaHS significantly decreased the mitochondrial permeability transition pore and increased mitochondrial membrane fluidity, mitochondrial membrane potential, and cytochrome $c / a$ ratio under $\mathrm{NaCl}$ stress. However, $0.02 \mathrm{mM}$ NaHS did not affect root growth, antioxidant enzyme activities, and mitochondrial function under $\mathrm{NaCl}$ stress, whereas high concentrations of $\mathrm{NaHS}$ (more than $0.2 \mathrm{mM}$ ) had a weaker or negative effects. Moreover, $15 \mu \mathrm{M}$ HT eliminated the beneficial effects of $\mathrm{NaHS}$ under $\mathrm{NaCl}$ stress. Our results suggest that $\mathrm{H}_{2} \mathrm{~S}$ protected plants against salt stress by decreasing $\mathrm{H}_{2} \mathrm{O}_{2}$ accumulation and by regulating membrane stability and antioxidant system in mitochondria.
\end{abstract}

Additional key words: apple, catalase, guiacol peroxidase, membrane potential, root elongation, superoxide dismutase.

\section{Introduction}

Salinity is one of the most serious environmental and ecological problems and limits plant germination, growth, productivity, and survival, especially in saline zones (Ferreira-Silva et al. 2012, Zhou et al. 2015). High salinity affects water potential and ion balance at both the cellular level and the entire plant level, disrupting homeostasis and contributing to osmotic, ionic, and oxidative stresses in plants (Banaei-Asl et al. 2015). Most terrestrial plants are extremely vulnerable to rhizosphere salinization, especially during the seedling period (Muhammad et al. 2017). Plant roots are the organ that absorbs nutrients and water from the growth substrate and are are strongly influenced by salinity, particularly during the germination period.

Mitochondria are responsible for oxidation of sugars, fats, and amino acids, for ATP synthesis, and they regulate oxidative stress, apoptosis, etc. (Huang et al. 2014). Mitochondria are also the principal location of reactive oxygen species (ROS) production, particularly in nonphotosynthetic cells such as root cells (Jacoby et al. 2012, Xia et al. 2015). Mitochondria are early targets of oxidative injuries, and environmental stress can cause mitochondrial damage and dysfunction (Ma et al. 2013). For example, nitrogen deficiency triggers accumulation of

Submitted 20 December 2017, last revision 15 June 2018, accepted 19 June 2018.

Abbrevations: ANS - 1-phenylamino-8-naphthalene sulfonic acid; BSA - bovine serum albumin; CAT - catalase; Cyt - cytochrome; EDTA - ethylenediamine tetraacetic acid; HEPES - N-2-hydroxyethylpiperazine-N-ethane-sulphonic acid; HT - hypotaurine; MDA malondialdehyde; MPTP - mitochondrial permeability transition pore; NaSH - sodium hydrosulfide; PCD - programmed cell death; POD - peroxidase; ROS - reactive oxygen species; SOD - superoxide dismutase; $\Delta \psi \mathrm{m}$ - mitochondrial membrane potential. Acknowledgements: This work was supported financially by the National Natural Science Foundation of China (grant Nos. 31772251 and 31372016) and the China National Key Technology R \& D Program (grant No. 2014BAD16B02).

* Author for correspondence; fax: (+86) 05388249304, e-mail: hqyang@sdau.edu.cn 
superoxide radical, hydrogen peroxide, and malondialdehyde (MDA) and increases mitochondrial lipid peroxidation under hypoxia stress (Sheng et al. 2009). The integrity of the mitochondrial ultrastructure decreases during ageing of oat seeds (Xia et al. 2015). Heat leads to the translocation of cytochrome $(\mathrm{Cyt}) c$ from mitochondria to the cytosol during programmed cell death in cucumber plants (Balk et al. 1999). Aluminum toxicity inhibits mitochondrial respiration, decreases ATP content, alters redox status, and destroys the internal structure, finally resulting in cell death in tobacco cells (Panda et al. 2008). Furthermore, it was reported that $\mathrm{NaCl}$ stress can also cause mitochondrial damage and dysfunction in plants. Stress caused by $\mathrm{NaCl}$ destroys the integrity of mitochondria, induces Cyt $c$ release from mitochondria into the cytosol, and inhibits electron transport, which results in oxidative burst in mitochondria (Chen et al. 2009). Treatment with $\mathrm{NaCl}$ leads to decrease of mitochondrial membrane potential $(\Delta \psi \mathrm{m})$ and $\mathrm{H}_{2} \mathrm{O}_{2}$ content in roots of Malus hupehensis seedlings (Ma et al. 2010). In previous studies, most researchers focused on the relationship between stress and mitochondrial function to reveal the mechanisms of stress injury. However, studies investigating how to enhance resistance by preventing or alleviating the damage on mitochondria need to be solved.

Hydrogen sulfide $\left(\mathrm{H}_{2} \mathrm{~S}\right)$ is an endogenous gaseous signaling molecule discovered in recent years. It plays an important role in improving plant cell adaptability to environmental stresses such as cold, drought, salinity, and heavy metals (Jin et al. 2011, Chen et al. 2013, Bharwana et al. 2014, Shan et al. 2014, Deng et al. 2016, Liu et al. 2016, Du et al. 2017). Studies have shown that $\mathrm{H}_{2} \mathrm{~S}$ dramatically increases the survival rate of Arabidopsis thaliana seedlings (Jin et al. 2011) and delays the accumulation of MDA, $\mathrm{H}_{2} \mathrm{O}_{2}$ and superoxide radical in

\section{Materials and methods}

Plants and treatments: Malus. hupehensis Rehd. var. pingyiensis is native in Taiyi mountain areas in Shandong province of China, and it is used as an apple rootstock. Uniform seeds were collected from the experimental field of the Shandong Agriculture University in the middle of October at the ripening time. Since M. hupehensis has a high degree of apomixis, the seedlings show little differences, and they are a good material for experiments. The seeds were surface sterilized in $75 \%(\mathrm{v} / \mathrm{v})$ ethanol for $2 \mathrm{~min}$ and in a $5 \%(\mathrm{~m} / \mathrm{v})$ sodium hypochlorite solution for an additional $10 \mathrm{~min}$ (Chen et al. 2013). After three washes with distilled water, seeds were immersed in distilled water at $25{ }^{\circ} \mathrm{C}$ for $12 \mathrm{~h}$, and then mixed with sand for stratification and maintained at $4{ }^{\circ} \mathrm{C}$ in a refrigerator for five weeks. The germinated seeds were selected and thoroughly rinsed with distilled water. To avoid a drastic damage, the germinated seeds were sprayed with $50 \mathrm{mM}$ $\mathrm{NaCl}$ and transferred to Petri dishes with double filter soybean seedlings (Zhang et al. 2010a) under drought stress. The $\mathrm{H}_{2} \mathrm{~S}$ also counteracts chlorophyll loss in sweet potato leaves, alleviates oxidative damage against osmotic stress (Zhang et al. 2009), improves heat tolerance in tobacco cell suspension ( $\mathrm{Li}$ et al. 2012, 2013), and alleviates root tip death induced by hypoxia in pea seedlings (Cheng et al. 2013). Furthermore, $\mathrm{H}_{2} \mathrm{~S}$ also plays an important role in plant responses to heavy metals including mercury (Chen et al. 2017), aluminum (Dawood et al. 2012, Chen et al. 2013), copper (Zhang et al. 2010b), boron (Wang et al. 2010), cadmium (Qiao et al. 2015, Tian et al. 2016), and zinc (Liu et al. 2016). It has been confirmed that $\mathrm{H}_{2} \mathrm{~S}$ plays a protective role against $\mathrm{NaCl}$ stress; for example, $\mathrm{H}_{2} \mathrm{~S}$ could attenuate the salt-induced inhibition of seed germination and seedling growth in alfalfa by reducing oxidative damage (Wang et al. 2012) and alleviates salt damage in maize leaves by enhancing ascorbate and glutathione metabolism (Shan et al. 2014). However, whether $\mathrm{H}_{2} \mathrm{~S}$ participates in regulation of mitochondrial antioxidant enzyme activities and mitochondrial function in plants under salt stress remains unknown.

Sodium hydrosulfide (NaHS), often used as an $\mathrm{H}_{2} \mathrm{~S}$ donor, and hypotaurine (HT), a scavenger of $\mathrm{H}_{2} \mathrm{~S}$ (Jin et al. 2011, Zhang et al. 2009, Li et al. 2012), were used in the current experiments. Root elongation, antioxidant enzyme activities, mitochondrial membrane permeability, membrane fluidity, membrane potential, and Cyt $c / a$ ratio as affected by $\mathrm{NaCl}$ and $\mathrm{NaHS}$ were investigated in the roots of Malus hupehensis var. pingyiensis. The aim of the study was to elucidate the impact of $\mathrm{H}_{2} \mathrm{~S}$ on mitochondrial function in salt-stressed plants and to provide a new insight into the role of $\mathrm{H}_{2} \mathrm{~S}$ in mitochondrial responses to salt stress.

paper pre-wetted with $50 \mathrm{mM} \mathrm{NaCl}$. After $12 \mathrm{~h}$, the pretreated germinated seeds were transferred to Petri dishes with double filter paper pre-wetted with different solutions. To analyze the effects of $\mathrm{H}_{2} \mathrm{~S}$, the $\mathrm{H}_{2} \mathrm{~S}$ donor $\mathrm{NaHS}$ and $\mathrm{H}_{2} \mathrm{~S}$ scavenger HT were added to an $85 \mathrm{mM}$ $\mathrm{NaCl}$ solution yielding seven combinations: 1) control (CK), 2) $85 \mathrm{mM} \mathrm{NaCl}$ alone, 3) $0.02 \mathrm{mM} \mathrm{NaHS}+85 \mathrm{mM}$ $\mathrm{NaCl}$, 4) $0.05 \mathrm{mM} \mathrm{NaHS}+85 \mathrm{mM} \mathrm{NaCl}$, 5) $0.10 \mathrm{mM}$ $\mathrm{NaHS}+85 \mathrm{mM} \mathrm{NaCl}$, б) $0.20 \mathrm{mM} \mathrm{NaHS}+85 \mathrm{mM} \mathrm{NaCl}$, and 7) $0.05 \mathrm{mM} \mathrm{NaHS}+15 \mu \mathrm{M} \mathrm{HT}+85 \mathrm{mM} \mathrm{NaCl}$. The control seeds were treated with distilled water. The germinated seeds were sprayed with these solutions twice a day. Cultures were maintained in a growth chamber at night/day temperatures of $22 / 25^{\circ} \mathrm{C}$, a relative humidity of $70-80 \%$, a photon flux intensity of $170 \mu \mathrm{mol} \mathrm{m} \mathrm{m}^{-2} \mathrm{~s}^{-1}$, and a 14-h photoperiod. Experiments were performed with a randomized complete block design, and every treatment was carried out with three replications, and every Petri dish 
was considered as a replicate. Root elongation, membrane stability, and antioxidant system in mitochondria were measured after seeds were grown under varying treatments for 24,48 , and $72 \mathrm{~h}$.

Root length was measured with a Vernier calliper before and after treatments. Root elongation $(\Delta \mathrm{L})$ was expressed as the change of the root length after treatment in comparison with that before the treatment. In addition, a relative root elongation was expressed as: $\operatorname{RRE~}[\%]=$ $\Delta \mathrm{L}$ (treatment group) $/ \Delta \mathrm{L}($ control group $) \times 100$.

Isolation of mitochondria was performed using the methods described by Panda et al. (2008) with some modifications. Root samples ( $5 \mathrm{~g}$ ) were thoroughly rinsed with distilled water and then homogenized with a buffer containing $400 \mathrm{mM}$ mannitol, $50 \mathrm{mM}$, Tris- $\mathrm{HCl}, 10 \mathrm{mM}$ $\mathrm{EDTANa}_{2}, 0.1 \%(\mathrm{~m} / \mathrm{v})$ bovine serum albumin, and $0.05 \%$ $(\mathrm{v} / \mathrm{v}) \beta$-mercaptoethanol, $\mathrm{pH} 7.4$, in an ice bath. The homogenate was centrifuged at $600 \mathrm{~g}$ and $4{ }^{\circ} \mathrm{C}$ for $10 \mathrm{~min}$, and the supernatant was collected and centrifuged again at $10000 \mathrm{~g}$ and $4{ }^{\circ} \mathrm{C}$ for $10 \mathrm{~min}$. The pellet containing mitochondria was washed with the same buffer and incubated on ice until used. The root mitochondria isolation was completed in $1 \mathrm{~h}$, and the isolated mitochondria were used within $2 \mathrm{~h}$. Mitochondria content was defined by their protein content, and protein content was determined by the Bradford (1976) method using BSA as a standard.

Measurement of $\mathrm{H}_{2} \mathrm{O}_{2}$ content and antioxidant enzyme activities: $\mathrm{H}_{2} \mathrm{O}_{2}$ content was determined with a titanium sulfate precipitation reaction (Panda et al. 2008). Isolated mitochondria were resuspended in a buffer $(50 \mathrm{mM}$ phosphate buffered saline, $5 \mathrm{mM} \mathrm{EDTANa}_{2}, \mathrm{pH}$ 7.4). A reaction mixture contained $20 \mathrm{~cm}^{3}$ of the mitochondrial suspension, $880 \mathrm{~cm}^{3}$ of double-distilled water, and $100 \mathrm{~cm}^{3}$ of titanium sulfate and was then incubated at room temperature for $15 \mathrm{~min}$. Absorbance at $415 \mathrm{~nm}$ was measured using a UV2550 (Shimadzu, Kyoto, Japan) spectrophotometer.

Superoxide dismutase (SOD, EC 1.15.1.1) activity was measured according to Giannopolitis et al. (1977). One unit of SOD activity was measured as the amount of enzyme required to cause $50 \%$ inhibition of the nitroblue tetrazolium (NBT) reduction measured at $560 \mathrm{~nm}$. Peroxidase (POD, EC1.11.1.7) activity was assayed as described by Kochba et al. (1977) with some modifications. A $3 \mathrm{~cm}^{3}$ of reactant mixture contained 200 $\mathrm{mM}$ potassium phosphate buffer $(\mathrm{pH} 6.0), 0.017 \%(\mathrm{v} / \mathrm{v})$ $\mathrm{H}_{2} \mathrm{O}_{2}, 0.038 \%$ (v/v) guaiacol, and $0.1 \mathrm{~cm}^{3}$ of the resuspended mitochondria. Variations in absorbance were measured at $470 \mathrm{~nm}$. Catalase (CAT, EC 1.11.1.6) activity was assayed according to Dhindsa et al. (1982).
Determination of mitochondrial permeability transition pore opening, membrane fluidity, and membrane potential: The mitochondrial inner membrane shows a high permeability for sucrose and mannitol because of the opening mitochondrial permeability transition pores (MPTPs), which leads to a decrease in absorbance at $540 \mathrm{~nm}$. This characteristics was measured according to $\mathrm{Hu}$ et al. (2015). Separated and purified mitochondrial pellets were suspended in a cooled MPTP test buffer (200 mM mannitol, $70 \mathrm{mM}$ sucrose, $5 \mathrm{mM}$ HEPES; pH 7.2). After a 2-min incubation at $20{ }^{\circ} \mathrm{C}$, absorbance at $540 \mathrm{~nm}$ was determined using a UV2550 (Shimadzu, Kyoto, Japan) spectrophotometer. Protein content determined by the Bradford method was adjusted to $0.3 \mathrm{mg} \mathrm{cm}^{-3}$.

Mitochondrial membrane fluidity was determined as described by Pan et al. (2016). The membrane surface was labeled with a fluorescent lipid probe 1-phenylamino-8naphthalene sulfonic acid (ANS). Isolated mitochondria were suspended in a buffer $(50 \mathrm{mM}$ phosphate buffered saline, $5 \mathrm{mM}$ EDTANa, $\mathrm{pH} 7.4)$. A $3 \mathrm{~cm}^{3}$ of the suspension was mixed with $0.3 \mathrm{mM}$ mannitol $\left(2.85 \mathrm{~cm}^{3}\right)$ and $5 \mathrm{mM}$ ANS $\left(0.06 \mathrm{~cm}^{3}\right)$ and after a 60 -s incubation, fluorescence was measured three times at 5-s intervals using a fluorescence spectrofluorometer (F4500, Shimadzu).

Measurement of mitochondrial membrane potential $\left(\Delta \psi_{\mathrm{m}}\right)$ was performed according to Zhan et al. (2014) with slight modifications. Isolated mitochondria were suspended in a buffer (250 mM sucrose, $2 \mathrm{mM} \mathrm{N}$-2-hydroxyethylpiperazine-N-ethane sulphonic acid (HEPES), $0.5 \mathrm{mM} \mathrm{KH} \mathrm{PO}_{4}, 4.2 \mathrm{mM}$ sodium succinic acid, $\mathrm{pH} 7.4$ ) and then stained with $1 \mu \mathrm{g} \mathrm{cm}^{-3}$ Rhodamine 123 in the dark at $25^{\circ} \mathrm{C}$ for $30 \mathrm{~min}$. The samples were centrifuged again at $10000 \mathrm{~g}$ and $4{ }^{\circ} \mathrm{C}$ for $10 \mathrm{~min}$ and washed three times in the buffer indicated above. After resuspension, fluorescence of each sample was measured three times at 5 -s intervals using a F4500 spectrofluorometer.

Detection of cytochrome $\boldsymbol{c} / \boldsymbol{a}$ ratio: The Cyt $c / a$ ratio was assessed as described by Tonshin et al. (2003). Isolated mitochondria were suspended in $0.2 \%(\mathrm{~m} / \mathrm{v}) \mathrm{BSA}$, and absorbances were measured at $550 \mathrm{~nm}$ and $630 \mathrm{~nm}$. Cyt $c / a$ was calculated by the ratio of absorbances at 550 and $630 \mathrm{~nm}$.

Statistical analyses: Each treatment was performed with three replicates. Results are presented as means \pm standard deviations (SDs). Two-way analysis of variance (ANOVA) was performed using the software Excel, SPSS 19.0, and SigmaPlot 10.5. Post hoc comparisons were performed using the Tukey least-significant difference (LSD) test at $\alpha=0.05$. 


\section{Results}

To assess the effects of $\mathrm{NaCl}$ stress on $M$. hupehensis, we measured root length after seed germination at $85 \mathrm{mM}$ $\mathrm{NaCl}$ for $72 \mathrm{~h}$ (Fig. 1 Suppl.). The root elongation was significantly inhibited by this $\mathrm{NaCl}$ treatment (Fig. 1). Further, we found that $0.02,0.05$, or $0.1 \mathrm{mM} \mathrm{NaHS}$ positively affected root growth, and $0.05 \mathrm{mM} \mathrm{NaHS}$ treatment had the greatest effect. The relative root elongation increased by $29.46,71.89$, and $70.40 \%$ at 24,48 , and $72 \mathrm{~h}$, respectively, in comparison with $\mathrm{NaCl}$ alone (Fig. 1). However, a high NaHS concentration (0.2 $\mathrm{mM}$ ) did not affect the root elongation under $\mathrm{NaCl}$ stress. The addition of HT to $0.05 \mathrm{mM}$ NaHS treatment canceled the positive effect of NaHS on root elongation (Fig. 1).

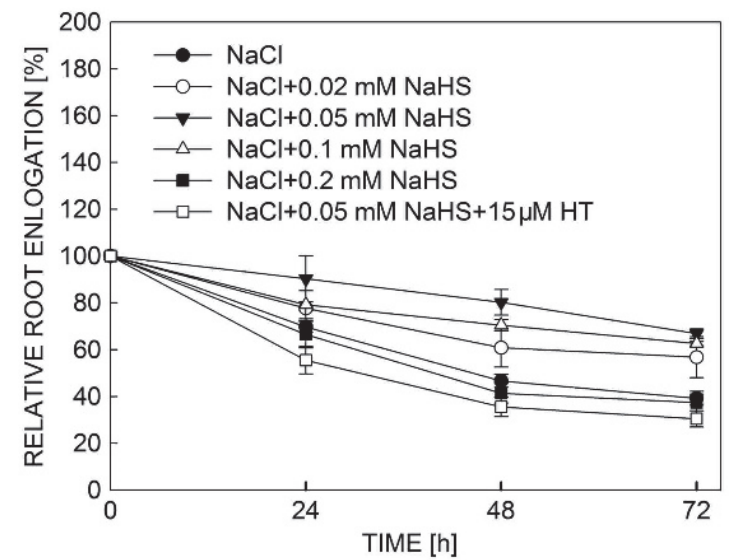

Fig. 1. The effect of NaHS on relative root elongation of Malus hupehensis seedling roots under $85 \mathrm{mM} \mathrm{NaCl}$ stress. Germinated seeds were treated with NaHS or hypotaurine (HT) at the indicated concentrations. Means \pm SDs, $n=3$, different letters indicate significant differences between treatments (LSD test, $\alpha=0.05)$.

Hydrogen peroxide originates from electron leakage in the electron transport chain in mitochondria, and from the production by SOD (Ma et al. 2013). The results show that $\mathrm{H}_{2} \mathrm{O}_{2}$ content in mitochondria decreased substantially up to $48 \mathrm{~h}$ and then rapidly accumulated at $72 \mathrm{~h}$ of $\mathrm{NaCl}$ stress. The application of $0.05 \mathrm{mM} \mathrm{NaHS}$ had the greatest effect on preventing $\mathrm{H}_{2} \mathrm{O}_{2}$ accumulation in mitochondria, which decreased by $31.63 \%$ at $24 \mathrm{~h}, 39.80 \%$ at $48 \mathrm{~h}$ and $37.30 \%$ at $72 \mathrm{~h}$ compared to treatment with $\mathrm{NaCl}$ alone. a low NaHS concentration $(0.02 \mathrm{mM})$ did not decrease obviously the $\mathrm{H}_{2} \mathrm{O}_{2}$ content. However, at an NaHS concentration above $0.2 \mathrm{mM}$, no extra positive effect was evident indicating that a high concentration of NaHS would be toxic. Furthermore, addition of HT eliminated the positive effect of $0.05 \mathrm{mM}$ NaHS in decreasing $\mathrm{H}_{2} \mathrm{O}_{2}$ content and resulted in similar effects as the $\mathrm{NaCl}$ treatment alone at $72 \mathrm{~h}$ (Fig. 2). These findings indicate that $\mathrm{H}_{2} \mathrm{~S}$ can reduce the accumulation of $\mathrm{H}_{2} \mathrm{O}_{2}$ in mitochondria under $\mathrm{NaCl}$ stress.

To investigate the effects of NaHS on the antioxidant system in mitochondria under $\mathrm{NaCl}$ stress, the activities of SOD, POD, and CAT were measured. All the activities were stimulated in the early stage of the $\mathrm{NaCl}$ stress, however, with the extending exposure to $\mathrm{NaCl}$ stress, the activities declined significantly at $72 \mathrm{~h}$ (Fig. 3). The treatments with $0.02-0.10 \mathrm{mM}$ NaHS could alleviate the $\mathrm{NaCl}$-induced decrease in SOD, POD and CAT activities after $72 \mathrm{~h}$, and the application with $0.05 \mathrm{mM} \mathrm{NaHS}$ showed the most significant effect. A high NaHS concentration $(0.2 \mathrm{mM})$ did not notably affect enzyme activities compared to the treatment by $\mathrm{NaCl}$ alone. However, when $\mathrm{H}_{2} \mathrm{~S}$ was scavenged with $\mathrm{HT}$, the positive effects of $0.05 \mathrm{mM}$ NaHS on the activities of SOD, POD and CAT in mitochondria were cancelled.

To investigate whether $\mathrm{H}_{2} \mathrm{~S}$ has an important

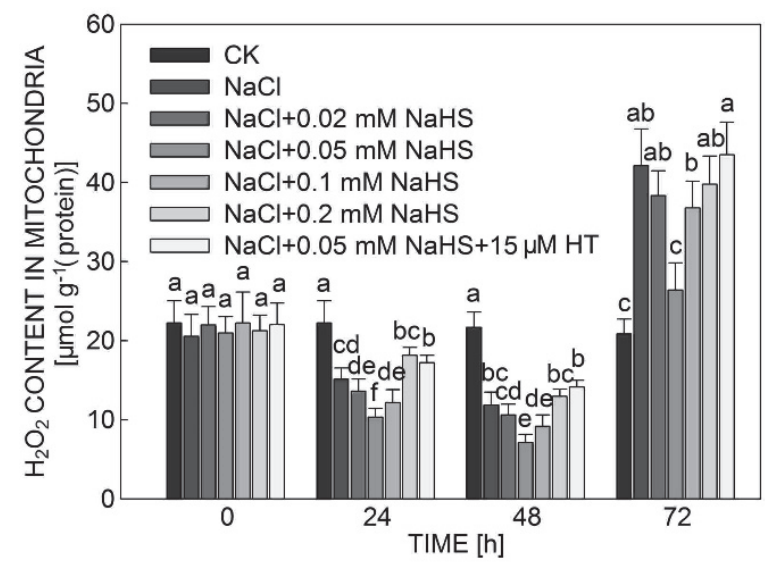

Fig. 2. The effect of NaHS on $\mathrm{H}_{2} \mathrm{O}_{2}$ content in mitochondria of Malus hupehensis seedling roots under $85 \mathrm{mM} \mathrm{NaCl}$ stress. Germinated seeds were treated with NaHS or hypotaurine (HT) at the indicated concentrations. Means \pm SDs, $n=3$, different letters indicate significant differences between treatments (LSD test, $\alpha=0.05$ ).

role in membrane stability in mitochondria, membrane fluidity, MPTP, $\Delta \psi \mathrm{m}$, and Cyt $c / a$ ratio were measured under $\mathrm{NaCl}$ stress. The fluorescence anisotropy of ANS was used to reflect membrane surface layer fluidity, with larger fluorescent values indicating lower membrane surface fluidity. The opening of MPTPs leads to a decrease in absorbance at $540 \mathrm{~nm}$ (Pan et al. 2016). Exposure to 85 $\mathrm{mM} \mathrm{NaCl}$ significantly increased fluorescence of ANS and decreased absorbance at $540 \mathrm{~nm}$ from $0 \mathrm{~h}$ to $72 \mathrm{~h}$ compared to the controls (Fig. $4 A, B$ ). The application of 0.02 or 0.05 $\mathrm{mM}$ NaHS significantly decreased fluorescence of ANS from $24 \mathrm{~h}$ to $72 \mathrm{~h}$ compared to treatment with $\mathrm{NaCl}$ alone (Fig. 4A). We found that $0.05 \mathrm{mM} \mathrm{NaHS}$ had the greatest effect on mitochondrial membrane fluidity under $\mathrm{NaCl}$ stress resulting in a decreased fluorescence of ANS by $29.37,42.10$, and $36.42 \%$ at 24,48 , and $72 \mathrm{~h}$, respectively. The application of $0.02,0.05$, or $0.1 \mathrm{mM} \mathrm{NaHS}$ increased absorbance at $540 \mathrm{~nm}$ under $\mathrm{NaCl}$ treatment, and $0.05 \mathrm{mM}$ 
NaHS had the greatest effect on inhibition of MPTP opening and significantly increased absorbance at $540 \mathrm{~nm}$ by $19.95,44.79$, and $129.68 \%$ at 24,48 , and $72 \mathrm{~h}$, respectively, compared to treatment with $\mathrm{NaCl}$ alone (Fig. 4B). However, concentrations of NaHS higher than $0.2 \mathrm{mM}$ had no effects or showed negative effects on mitochondrial membrane fluidity and MPTP opening under $\mathrm{NaCl}$ stress. Moreover, the effects of $0.05 \mathrm{NaHS}$ on mitochondrial membrane fluidity and MPTP opening were reduced following the application of $\mathrm{HT}$.

There were no obvious changes in mitochondrial

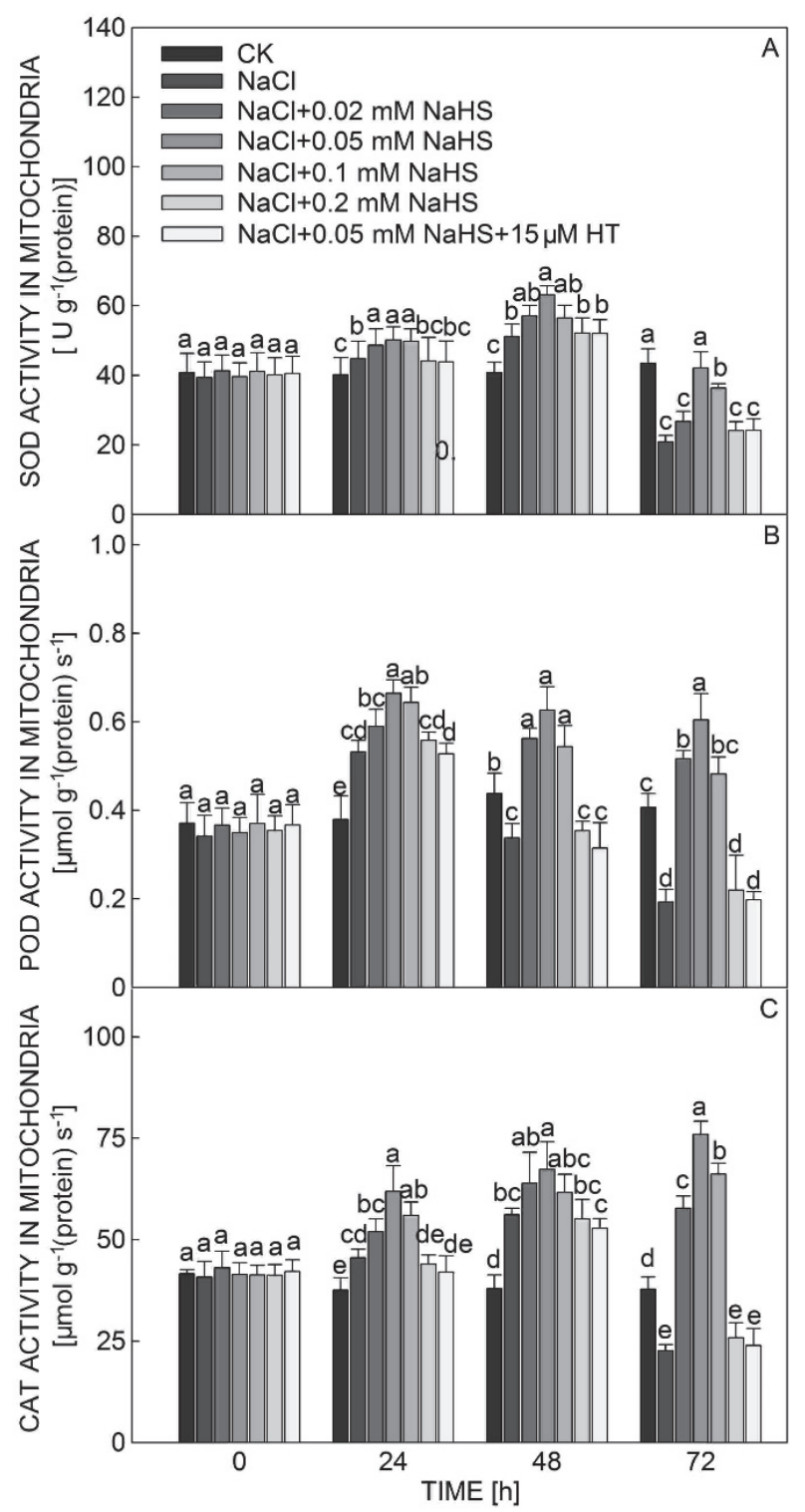

Fig. 3. The effect of NaHS on superoxide dismutase (SOD, $A$ ), peroxidase $(\mathrm{POD}, B)$, and catalase $(\mathrm{CAT}, C)$ activities in mitochondria of Malus hupehensis seedling roots under $85 \mathrm{mM}$ $\mathrm{NaCl}$ stress. Germinated seeds were treated with $\mathrm{NaHS}$ or hypotaurine (HT) at the indicated concentrations. Means \pm SDs, $n=3$, different letters indicate significant differences between treatments (LSD test, $\alpha=0.05$ ). membrane potential and Cyt $c / a$ ratio under control treatment from 0 to $72 \mathrm{~h}$. The $\mathrm{NaCl}$ stress significantly decreased $\Delta \psi \mathrm{m}$ and Cyt $c / a$ from 24 to $72 \mathrm{~h}$ compared to values in the controls (Fig. $4 C, D$ ). The application

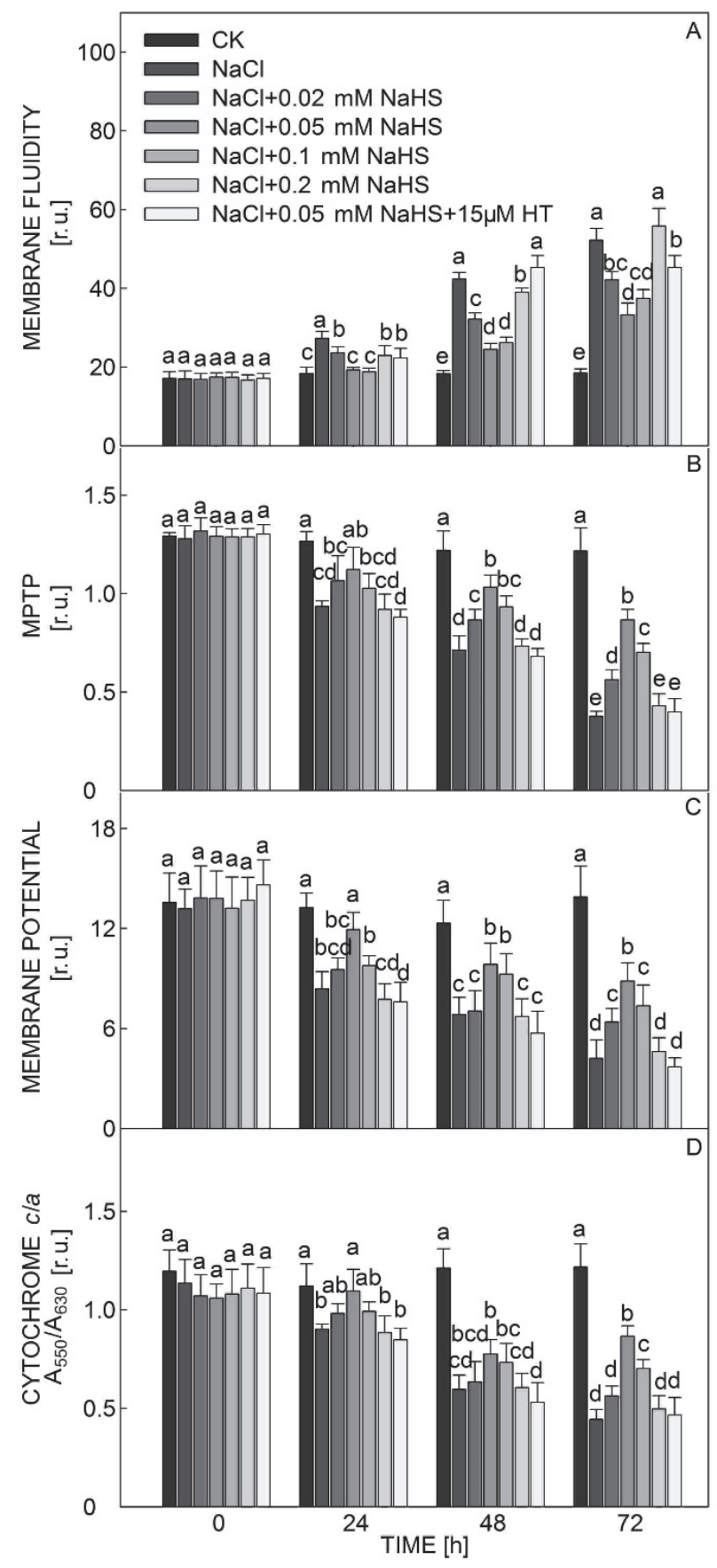

Fig. 4. The effect of NaHS on membrane fluidity $(A)$, mitochondrial permeability transition pore (MPTP, $B$ ), membrane potential $(C)$, and Cyt $c / a$ ratio $(D)$ in mitochondria of Malus hupehensi seedling roots under $85 \mathrm{mM} \mathrm{NaCl}$ stress. Germinated seeds were treated with NaHS or hypotaurine (HT) at the indicated concentrations. Means \pm SDs, $n=3$, different letters indicate significant differences between treatments (LSD test, $\alpha=0.05$ ). 
of $0.05 \mathrm{mM}$ NaHS significantly increased $\Delta \psi \mathrm{m}$ and Cyt $c / a$ from $24 \mathrm{~h}$ to $72 \mathrm{~h}$ compared to the treatment with $\mathrm{NaCl}$ alone and other NaHS treatments. The $\Delta \psi \mathrm{m}$ and Cyt $c / \mathrm{a}$ values at $0.05 \mathrm{mM}$ NaHS increased of 42.31, 44.05, and $110.13 \%$; and $21.34,30.31$, and $95.20 \%$ at 24,48 , and $72 \mathrm{~h}$, respectively, compared to treatment with $\mathrm{NaCl}$ alone. In addition, the effects of $0.01 \mathrm{mM}$ and $0.02 \mathrm{NaHS}$ were time-dependent; germinated seeds pre-treated with significant change in $\Delta \psi \mathrm{m}$ at $72 \mathrm{~h}$ and $48 \mathrm{~h}$ of treatment, respectively, compared to treatment with $\mathrm{NaCl}$ alone. In addition, $0.1 \mathrm{mM}$ NaHS exhibited a significant effect on Cyt $c / a$ only at $48 \mathrm{~h}$ of treatment. A higher concentration of NaHS $(0.2 \mathrm{mM})$ showed no effects or negative effects on mitochondrial membrane potential and Cyt $c / a$ under $\mathrm{NaCl}$ stress. Moreover, the effects of $0.05 \mathrm{NaHS}$ were alleviated when HT was added.

\section{Discussion}

The mitochondrial electron transport chain is a major site of ROS formation, especially in non-photosynthetic cells of root tissues (Amirsadeghi et al. 2006), and it may participate in oxidative burst in plants (Huang et al. 2014). Environmental stresses, such as salinity, result in the overproduction of ROS in plants (Zhang et al. 2007, Huang et al. 2014). In the present study, inhibited root elongation, decreased antioxidant system and membrane stability in mitochondria were observed in the seedling roots of $M$. hupehensis in response to $\mathrm{NaCl}$ stress. However, under short stress conditions, the low $\mathrm{H}_{2} \mathrm{O}_{2}$ content observed in mitochondria treated with $0.05 \mathrm{mM}$ NaHS was probably due to the stimulation of antioxidative enzymes. This was proved by the increase in SOD, POD, and CAT activities in mitochondria after 24 to $48 \mathrm{~h}$ of $\mathrm{NaCl}$ or $\mathrm{NaCl}+\mathrm{NaHS}$ treatments. In our study, $\mathrm{H}_{2} \mathrm{~S}$ alleviated the $\mathrm{NaCl}$ caused oxidative stress by increasing activities of ROS scavenging enzymes and also played an important role in alleviating $\mathrm{NaCl}$-induced inhibition of root elongation. Similar results were also reported when the role of $\mathrm{H}_{2} \mathrm{~S}$ in alleviating the toxicity of drought and heavy metals was investigated (Zhang et al. 2010a,b). It has been elaborated that plants have two ways to defense against ROS accumulation (Chongchatuporn et al. 2013), the first way is antioxidative enzymes, such as SOD, POD, and CAT, and the second way is non-enzymatic compounds, such as ascorbate and glutathione, so, it is necessary to further investigate the effects of $\mathrm{H}_{2} \mathrm{~S}$ on nonenzymatic antioxidants in mitochondria under $\mathrm{NaCl}$ stress. However, with a more severe stress, the scavenging system may become saturated by the increased rate of ROS production, ultimately leading to excessive ROS production (Zhang et al. 2010b). In this study, with an increased treatment time, SOD, POD, and CAT activities decreased indicating that the antioxidant defence system failed to completely scavenge excessive ROS, and so $\mathrm{H}_{2} \mathrm{O}_{2}$ content drastically increased at 72 h (Figs. 2 and 3). An increased ROS amount induces sustained MPTP opening (Szabo and Zoratti 2014) and results in ROS burst in a phenomenon known as ROS-induced ROS release, which eventually leads to a severe mitochondrial damage or cell death (Zorov et al. 2014), followed by more Cyt $c$ release. The release of Cyt $c$ from mitochondria could disrupt the respiratory electron transport chain, and this phenomenon can increase ROS content, which in turn affects Cyt $c$ release (Wang et al. 2014). Furthermore, excessive ROS could directly interact with mitochondrial proteins and lipids, causing their dysfunction and decreasing $\Delta \psi \mathrm{m}$ and mitochondrial membrane fluidity (Huang et al. 2014). The major site of ROS formation in mitochondria lies in the electron transport chain, especially at Complex I and Complex III in state 4 mitochondrial respiration (Chen et al. 2003). However, state 4 mitochondrial respiration is regulated by $\Delta \psi \mathrm{m}$; thus, a $\Delta \psi \mathrm{m}$ drop increases electron leakage (Ichas and Mazat 1998), which ultimately led to excessive ROS generation at $72 \mathrm{~h}$ and further to MPTP opening, decreased mitochondrial membrane fluidity, and loss of $\Delta \psi \mathrm{m}$. These changes resulted in mitochondrial swelling and rupture of the outer mitochondrial membrane and could explain the inhibition of root elongation under $\mathrm{NaCl}$ stress. The integrity of mitochondria decreases and release of cyt $\mathrm{c}$ has also been observed in rice under salt stress (Chen et al. 2009).

Hydrogen sulfide, the third endogenous gaseous transmitter after nitric oxide and carbon monoxide, was proved to play a role in alleviating biotic and abiotic stresses (Qian et al. 2014). Previous studies showed that $\mathrm{H}_{2} \mathrm{~S}$ is involved in responses to salt stress by alleviating an $\mathrm{NaCl}$-induced increase of MDA content and electrolyte leakage, and by regulating ascorbate and glutathione metabolism in maize (Shan et al. 2014). Lai et al. (2014) also found that endogenous $\mathrm{H}_{2} \mathrm{~S}$ enhances $\mathrm{NaCl}$ tolerance by maintaining $\mathrm{K}^{+} / \mathrm{Na}^{+}$homeostasis through preventing the NaCl-triggered $\mathrm{K}^{+}$efflux, and modulated several genes/activities of antioxidant defence enzymes in alfalfa seedlings. In our study, we used $0,0.02,0.05,0.1$, and 0.2 $\mathrm{mM}$ NaHS, and we found that $0.05 \mathrm{mM}$ NaHS treatment significantly improved SOD, POD, and CAT activities and decreased $\mathrm{H}_{2} \mathrm{O}_{2}$ content in mitochondria under $\mathrm{NaCl}$ stress, even after long-term salt stress treatment (Fig. 2,3), and these results are in agreement with those of Shan et al. (2014) and Lai et al. (2014). However, little information is known about the role of $\mathrm{H}_{2} \mathrm{~S}$ in membrane stability in mitochondria. In our study, it was proved that $0.05 \mathrm{mM}$ NaHS could significantly inhibit MPTP opening and improve mitochondrial membrane fluidity under salt stress. Moreover, $\Delta \psi \mathrm{m}$ and Cyt $c / a$ also increased when plants were treated with $\mathrm{NaHS}$, indicating the protective 
role of $\mathrm{H}_{2} \mathrm{~S}$ against the salt-induced damage of mitochondrial membranes in roots (Fig. 4). Since increasing evidences indicate that mitochondria play a pivotal role in programmed cell death (PCD) in plants, and ROS burst, MPTP opening, and $\Delta \psi \mathrm{m}$ loss are early markers of PCD induced by various stimuli (Yao et al. 2004). We suspected that $\mathrm{H}_{2} \mathrm{~S}$ also participated in PCD in the plants. Moreover, $\mathrm{H}_{2} \mathrm{~S}$ can eliminate oxygen radicals by restoring the disulphide bond. In addition, it has been proved in animals that sulfhydryl (-SH) can combine with harmful substances such as oxygen free radicals, electrophilic bases and metal ions to reduce cell damage, as well as to enhance cell recovery (Wang et al. 2014).

Numerous results demonstrated that exogenous $\mathrm{H}_{2} \mathrm{~S}$ participates in plant adaptive responses to multiple abiotic stresses via stimulation of antioxidative enzymes (Chen et al. 2013) or non-enzymatic antioxidants (Shan et al. 2014), however, the molecular mechanisms of $\mathrm{H}_{2} \mathrm{~S}$ signaling are still limited. As $\mathrm{H}_{2} \mathrm{~S}$ can interacts with the sulfhydryl groups of selective proteins, yielding a hydropersulfide moiety (-SSH) in a process termed S-sulfhydration, more and more evidence shows that S-sulfhydration is an important redox signalling

\section{Conclusions}

In this study, $\mathrm{H}_{2} \mathrm{~S}$ played an important role in alleviating the $\mathrm{NaCl}$-induced inhibition of root elongation in M. hupehensis Rehd. var. pingyiensis. However, the effects of $\mathrm{H}_{2} \mathrm{~S}$ were dependent on its concentration. Our results demonstrate that $0.05 \mathrm{mM} \mathrm{NaHS}$ showed the optimal effects and strongly enhanced the antioxidant mechanism (Kabil et al. 2010, Yang et al. 2013) which has been proved in animals. Krishnan et al. (2011) found that $\mathrm{H}_{2} \mathrm{~S}$ can inhibit PTP1B, the prototypic member of protein tyrosine phosphatases (PTPs) enzyme family, via sulfhydration of the active site Cys in PTP1B in cells required the presence of cystathionine- $\gamma$-lyase (CSE), a critical enzyme in $\mathrm{H}_{2} \mathrm{~S}$ production, and resulted in inhibition of phosphatase activity in endoplasmic reticulum stress of mouse. Yang et al. (2013) found that $\mathrm{H}_{2} \mathrm{~S}$ protects cells against senescence via $\mathrm{S}$-sulfhydration of Kelch-like ECH-associated protein 1 (Keap1) and then activates nuclear factor-E2-related factor2 (Nrf2) to respond to oxidative stress in mouse. In our study, the results show that exogenous $\mathrm{H}_{2} \mathrm{~S}$ treatment can reduce the opening of the MPTP under $\mathrm{NaCl}$ stress, maybe also due to that $\mathrm{H}_{2} \mathrm{~S}$ can maintain the original structure of MPTP via S-sulfhydration. Liu et al. (2015) also suggested that $\mathrm{H}_{2} \mathrm{~S}$ participates in responses to low temperature, heat, salt, osmotic, and UV stresses by mediating protein Ssulfhydration in foxtail millet. However, knowledge of the $\mathrm{H}_{2} \mathrm{~S}$-induced S-sulfhydration in the response to stress in plants require further investigation.

\section{References}

Amirsadeghi, S., Robson, C.A., McDonald, A.E., Vanlerberghe, G.C.: Changes in plant mitochondrial electron transport alter cellular levels of reactive oxygen species and susceptibility to cell death signaling molecules. - Plant Cell Physiol. 47: 1509-1519, 2006.

Balk, J., Leaver, C.J., McCabe, P.F.: Translocation of cytochrome $c$ from the mitochondria to the cytosol occurs during heat-induced programmed cell death in cucumber plants. - FEBS Lett. 463: 151-154, 1999.

Banaei-Asl, F., Bandehagh, A., Uliaei, E.D., Farajzadeh, D., Sakata, K., Mustafa, G., Komatsu, S.: Proteomic analysis of canola root inoculated with bacteria under salt stress. - J. Proteomics 124: 88-111, 2015.

Bharwana, S.A., Ali, S., Farooq, M.A., Ali, B., Iqbal, N., Abbas, F., Ahmad, M.S.A.: Hydrogen sulfide ameliorates leadinduced morphological, photosynthetic, oxidative damages and biochemical changes in cotton. - Environ. Sci. Pollut. Res. Int. 21: 717-731, 2014.

Bradford, M.M.: A rapid and sensitive method for quantification of microgram quantities of protein utilizing the principle of protein-dye-binding. - Anal. Biochem. 72: 248-254, 1976.

Chen, J., Wang, W.H., Wu, F.H., You, C.Y., Liu, T.W., Dong, system and membrane stability in mitochondria, as evidenced by increased SOD, POD and CAT activities, decreased endogenous $\mathrm{H}_{2} \mathrm{O}_{2}$ content, decreased mitochondrial membrane permeability, and increased mitochondrial membrane fluidity, membrane potential, and Cyt $c / a$ ratio under $\mathrm{NaCl}$ stress.
X.J.: Hydrogen sulfide alleviates aluminum toxicity in barley seedlings. - Plant Soil 362: 301-318, 2013.

Chen, Q., Vazquez, E.J., Moghaddas, S.: Production of reactive oxygen species by mitochondria: central role of complex III. - J. biol. Chem. 278: 36027-36031, 2003.

Chen, X., Wang, Y., Li, J.Y., Jiang, A.L., Cheng, Y.W., Zhang, W.: Mitochondrial proteome during salt stress-induced programmed cell death in rice. - Plant Physiol. Biochem. 47: 407-415. 2009.

Chen, Z., Chen, M., Jiang, M.: Hydrogen sulfide alleviates mercury toxicity by sequestering it in roots or regulating reactive oxygen species productions in rice seedlings. - Plant Physiol. Biochem. 111: 179-192, 2017.

Cheng, W., Zhang, L., Jiao, C.J., Su, M., Yang, T., Zhou, L.N., Peng, R.Y., Wang, R.R., Wang, C.Y.: Hydrogen sulfide alleviates hypoxia-induced root tip death in Pisum sativum. Plant Physiol. Biochem. 70: 278-286, 2013.

Chongchatuporn, U., Ketsa, S., Van Doorn, W.G.: Chilling injury in mango (Mangifera indica) fruit peel: relationship with ascorbic acid concentrations and antioxidant enzyme activities. - Postharvest Biol. Technol. 86: 409-417, 2013.

Dawood, M., Cao, F., Jahangir, M.M., Zhang, G., Wu, F.: 
Alleviation of aluminum toxicity by hydrogen sulfide is related to elevated ATPase, and suppressed aluminum uptake and oxidative stress in barley. - J. Hazard. Mater. 209-210: 121-128, 2012.

Deng, Y.Q., Bao, J., Yuan, F., Liang, X., Feng, Z.T., Wang, B.S.: Exogenous hydrogen sulfide alleviates salt stress in wheat seedlings by decreasing $\mathrm{Na}^{+}$content. - Plant Growth Regul. 79: 391-399, 2016.

Dhindsa, R.S., Plumb-Dhindsa, P., Thorpe, T.A.: Leaf senescence correlated with increased levels of membrane permeability and lipid peroxidation, and decreased levels of superoxide dismutase and catalase. - J. exp. Bot. 32: 93-101, 1982.

Du, X.Z., Jin, Z.P., Liu, D.M., Yang, G.D., Pei, Y.X.: Hydrogen sulfide alleviates the cold stress through MPK4 in Arabidopsis thaliana. - Plant Physiol. Biochem. 120: 112119, 2017.

Ferreira-Silva, S.L., Voigt, E.L., Silva, E.N., Maia, J. M., Aragão, T.C.R., Silveira, J.A.G.: Partial oxidative protection by enzymatic and non-enzymatic components in cashew leaves under high salinity. - Biol. Plant. 56: 172-176, 2012.

Gioniannopolitis, C.N., Ries, S.K.: Purification and quantitative relationship with water-soluble protein in seedling. - Plant Physiol. 59: 315-318, 1977.

Hu, Z.G., Zhou, L., Ding, S.Z.: Effects of aerobic training to exhaustive exercise rat mitochondrial permeability transition pore. - J. Shenyang Sport Univ. 34: 64-67, 2015.

Huang, W.J., Yang, X.D., Yao, S.C., Thet, L.O., He, H.Y., Wang, A.Q., Li, C.Z., He, L.F.: Reactive oxygen species burst induced by aluminum stress triggers mitochondria-dependent programmed cell death in peanut root tip cells. - Plant Physiol. Biochem. 82: 76-84, 2014.

Ichas, F., Mazat, J.P.: From calcium signaling to cell death: two conformation for the mitochondrial permeability transition pore. Switching from low- to high-conductance state. Biochim. Biophys. Acta 1366: 33-50, 1998.

Jacoby, R.P., Li, L., Huang, S., Lee, C.P., Millar, A.H., Taylor, N.L.: Mitochondrial composition, function and stress response in plants. - J. integr. Plant Biol. 54: 887-906, 2012.

Jin, Z.P., Shen, J.J., Qiao, Z.J., Yang, G.D., Wang, R., Pei, Y. X.: Hydrogen sulfide improves drought resistance in Arabidopsis thaliana. - Biochem. biophys. Res. Co. 414: 481-486, 2011.

Kabil, O., Banerjee, R.: Redox biochemistry of hydrogen sulfide. - J. biol. Chem. 285: 21903-21907, 2010.

Kochba, J., Lavee, S., Spiegel-Roy, P.: Differences in peroxidase activity and isoenzymes in embryogenic and nonembryogenic 'Shamouti' orange ovular callus lines. - Plant Cell Physiol. 18: 463-467, 1977.

Krishnan, N., Fu, C.X., Pappin, D.J., Tonks, N.K.: $\mathrm{H}_{2} \mathrm{~S}$-induced sulfhydration of the phosphatase PTP1B and its role in the endoplasmic reticulum stress response. - Sci. Signal. 4: ra86, 2011.

Lai, D.W., Mao, Y., Zhou, H., Li, F., Wu, M.Z., Zhang, J., He, Z.Y., Cui, W.T., Xie, Y.J.: Endogenous hydrogen sulfide enhances salt tolerance by coupling the reestablishment of redox homeostasis and preventing salt-induced $\mathrm{K}^{+}$loss in seedlings of Medicago sativa. - Plant Sci. 225: 117-129, 2014.

Li, Z.G., Ding, X.J., Du, P.F.: Hydrogen sulfide donor sodium hydrosulfide improved heat tolerance in maize and involvement of proline. - Plant Physiol. 170: 741-747, 2013.

Li, Z.G., Gong, M., Xie, H., Yang, L., Li, J.: Hydrogen sulfide donor sodium hydrosulfide-induced heat tolerance in tobacco
(Nicotiana tabacum L) suspension cultured cells and involvement of $\mathrm{Ca}^{2+}$ and calmodulin. - Plant Sci. 185/186: 185-189, 2012.

Liu, X., Chen, J., Wang, G.H., Wang, W.H., Shen, Z.J., Luo, M.R., Gao, G.F., Simon, M., Ghoto, K., Zheng, H.L.: Hydrogen sulfide alleviates zinc toxicity by reducing zinc uptake and regulating genes expression of antioxidative enzymes and metallothioneins in roots of the cadmium/zinc hyperaccumulator Solanum nigrum L. - Plant Soil 400: 177192, 2016.

Liu, Z.Q., Pei, Y.X., Fang, H.H., Tian, B.H.: $\left[\mathrm{H}_{2} \mathrm{~S}\right.$ regulates foxtail millet responding to stress by protein $\mathrm{S}$ sulfhydration.] - Chin. J. Biochem. Mol. Biol. 31: 1085-1091, 2015. [In Chin., ab: E]

Ma, H.Y., Lv, D.G., Liu, G.C.: Mitochondrial response in the apical and lateral flower buds of the Hanfu apple to cold stress during the dormancy stage. - Acta ecol. Sin. 33: 52-58, 2013.

Ma, H.Y., Lv, D,G., Yang H.Q.: Characteristics of mitochondria and cell death in roots of Malus hupehensis var. pingyiensis under $\mathrm{NaCl}$ stress. - Chin. J. Plant Ecol. 34: 1448-1453, 2010.

Muhammad, F., Nirmali, G., Mubshar, H., Sharmistha, B., Sreyashi, P., Nandita, B., Hussein, M.M., Salem, S.A., Kadambot, H.M.S.: Effects, tolerance mechanisms and management of salt stress in grain legumes. - Plant Physiol. Biochem. 118: 199-217, 2017.

Pan, X.B., Xiang, L.X., Hu, X.H., Ren, W.Q., Zhang, L., Ni, X.X.: Effects of exogenous spermidine on mitochondrial function of tomato seedling roots under salinity-alkalinity stress. - Chin. J. Plant Ecol. 27: 491-498, 2016. [In Chin., ab: E]

Panda, S.K., Yamamoto, Y., Kondo, H., Matsumoto, H.: Mitochondrial alterations related to programmed cell death in tobacco cells under aluminium stress. - Compt. rend. Biol. 331: 597-610, 2008.

Qiao, Z.J., Jing, T., Liu, Z.Q., Zhang, L.P., Jin, Z.P., Liu, D.M., Pei, Y.X.: $\mathrm{H}_{2} \mathrm{~S}$ acting as a downstream signaling molecule of SA regulates Cd tolerance in Arabidopsis. - Plant Soil 393: 137-146, 2015.

Qian, P., Sun, R., Ali, B., Gill, R.A., Xu, L., Zhou, W.J.: Effects of hydrogen sulfide on growth, antioxidative capacity, and ultrastructural changes in oilseed rape seedlings under aluminum toxicity. - J. Plant Growth Regul. 33: 526-538, 2014.

Shan, C., Liu, H., Zhao, L., Wang, X.: Effects of exogenous hydrogen sulfide on the redox states of ascorbate and glutathione in maize leaves under salt stress. - Biol. Plant. 58: 169-173, 2014.

Sheng, L.X., Feng, L.G., Shu, H.R.: Effets of nitrogen on the activity of antioxidant enzymes and functions of mitochondriain cherry rootstock roots under hypoxia stress. Acta horticult. sin. 36: 1575-1580, 2009 [In Chin., ab: E].

Szabo, I., Zoratti, M.: Mitochondrial channels: ion fluxes and more. - Physiol. Rev. 94: 519-608, 2014.

Tian, B.H., Qiao, Z.J., Zhang, L.P., Hua, L., Pei, Y.X.. Hydrogen sulfide and proline cooperate to alleviate cadmium stress in foxtail millet seedlings. - Plant Physiol. Biochem. 109: 293299, 2016.

Tonshin, A.A., Saprunova, V.B., Solodovnikova, I.M.. Functional activity and ultrastructure of mitochondrial isolated from myocardial apoptotic tissue. - Biochemistry $\mathbf{6 8}$ : 875-881, 2003.

Wang, B.L., Shi, L., Li, Y.X., Zhang, W.H.: Boron toxicity is 
alleviated by hydrogen sulphide in cucumber (Cucumis sativus L.) seedlings. - Planta 231: 1301-1309, 2010.

Wang, J., Zhu, H., Liu, X., Liu, Z.: Oxidative stress and $\mathrm{Ca}^{2+}$ signals involved on cadmium-induced apoptosis in rat hepatocyte. - Biol. Trace Element Res. 161: 180-189, 2014.

Wang, Y.Q., Li, L., Cui, W.T., Xu, S., Shen, W.B., Wang, R.: Hydrogen sulfide enhances alfalfa (Medicago sativa) tolerance against salinity during seed germination by nitric oxide pathway. - Plant Soil 351: 107-119, 2012.

Xia, F.S., Wang, X.G., Li, M.L., Mao, P.S.: Mitochondrial structural and antioxidant system responses to aging in oat (Avena sativa L.) seeds with different moisture contents. Plant Physiol. Biochem. 94: 122-129, 2015.

Yang, G.D., Zhao, K.X., Ju, Y.J., Mani, S., Cao, Q.H., Puukila, S., Khaper, N., Wu, L.Y., Wang, R.: Hydrogen sulfide protects against cellular senescence via S-sulfhydration of Keap1 and activation of Nrf2. - Antioxid Redox Signal. 18: 1906-1919, 2013.

Yao, N., Eisfelder, B.J., Marvin, J., Greenberg, J.T.: The mitochondrion - an organelle commonly involved in programmed cell death in Arabidopsis thaliana. -Plant J. 40: 596-610, 2004.

Zhan, J., Li, W., He, H.Y., Li, C.Z., He, L.F.: Mitochondrial alterations during Al-induced PCD in peanut root tips. - Plant Physiol. Biochem. 75: 105-113, 2014.
Zhang, F., Wang, Y., Lou, Z., Dong, J.: Effect of heavy metal stress on antioxidative enzymes and lipid peroxidation in leaves and roots of two mangrove plant seedlings (Kandelia candel and Bruguiera gymnorrhiza). - Chemosphere 67: 4450, 2007.

Zhang, H., Hu, L.Y., Hu, K.D., He, Y.D., Wang, S.H., Luo, J.P.: Hydrogen sulfide promotes wheat seed germination and alleviates oxidative damage against copper stress. - J. integr. Plant Biol. 50: 1518-1529, $2010 \mathrm{~b}$.

Zhang, H., Jiao, H., Jiang, C.X., Wang, S.H., Wei, Z.J., Luo, J.P., Jones, R.L.: Hydrogen sulfide protects soybean seedlings against drought-induced oxidative stress. - Acta Physiol. Plant. 32: 849-857, 2010a.

Zhang, H., Ye, Y.K., Wang, S.H., Luo, J.P., Tang, J., Ma, D.F.: Hydrogen sulfide counteracts chlorophyll loss in sweet potato seedling leaves and alleviates oxidative damage against osmotic stress. - Plant Growth Regul. 58: 243-250, 2009.

Zhou, L., Wang N.N., Gong, S.Y., Lu, R., Li, Y., Li, X.B.: Overexpression of a cotton (Gossypium hirsutum) WRKY gene, GhWRKY34, in Arabidopsis enhances salt tolerance of the transgenic plants. - Plant Physiol. Biochem. 96: 311-320, 2015.

Zorov, D.B., Juhaszova, M., Sollott, S.J.: Mitochondrial reactive oxygen species (ROS) and ROS-induced ROS release. Physiol. Rev. 94: 909-950, 2014. 